\title{
GESTIÓN SANITARIA Y RESISTENCIA A LOS ANTIMICROBIANOS EN ANIMALES DE PRODUCCIÓN
}

\author{
María de los Angeles Gatica Eguiguren¹,a, Hernán Rojas 1,b
}

\begin{abstract}
RESUMEN
Los importantes beneficios de los antimicrobianos en el control de enfermedades los han transformado en una herramienta fundamental en la producción animal. Sin embargo, su elevado uso y, muchas veces, mal uso, ha contribuido a uno de los principales problemas de la salud pública a nivel mundial: la resistencia a los antimicrobianos. A nivel de la producción animal, las aplicaciones de manejos sanitarios permiten disminuir la necesidad de uso de antimicrobianos y en caso de necesitar su utilización, las buenas prácticas reducen al mínimo la posibilidad de generar resistencia. A pesar de esto, es necesario la aplicación y el desarrollo de nuevas estrategias que permitan enfrentar el problema de manera intersectorial, integrando a todos los participantes del sector público y privado.
\end{abstract}

Palabras clave: Producción agropecuaria; Acuicultura; Antibacterianos; Resistencia a antibióticos; Control sanitario (fuente: DeCS BIREME)

\section{SANITARY MANAGEMENT AND RESISTANCE TO ANTIMICROBIAL AGENTS IN PRODUCTION ANIMALS}

\begin{abstract}
The important benefits of antimicrobial agents in disease control have turned them into a fundamental tool in animal production. Nevertheless, its elevated use and, often, misuse, has contributed to one of the main public health problems in the world: resistance to antimicrobial agents. At the animal production level, the applications in terms of health management allow decreasing the need to use antimicrobial agents and, in the cases where they are needed, the good practices reduce their potential to cause resistance to a minimum. Despite this, the application and development of new strategies that allow facing the problem on a trans-sectoral basis are required, integrating all participants in the public and private sector.
\end{abstract}

Keywords: Livestock industry; Aquaculture; Anti-Bacterial agents; Drug resistance, microbial; Health surveillance (source: MeSH NLM)

\section{INTRODUCCIÓN}

El uso excesivo e inadecuado de los antimicrobianos (AM) en la población humana y animal conduce a la selección y multiplicación de bacterias resistentes ${ }^{(1)}$. Su acelerado avance lo ha posicionado como uno de los problemas de salud pública más importantes a nivel mundial, ocupando un espacio en la agenda política de países y organizaciones internacionales.

Según la declaración de la Organización Mundial de la Salud (OMS), a pesar que los AM han sido una herramienta vital para el tratamiento y control de infecciones bacterianas en humanos, las consecuencias de la resistencia a los antimicrobianos (RAM) en la salud pública son enormes y ampliamente discutidas. Sin embargo, estas son mayormente desconocidas en la producción animal, destacándose un incremento de la morbilidad y mortalidad, además de serios efectos en la eficiencia productiva ${ }^{(2)}$.

Tal como lo mencionan muchos organismos internacionales, el impacto de la RAM en el bienestar humano, animal yambiental obligan a actuar bajo el enfoque Una Salud (3), donde, los esfuerzos aislados no tendrían el impacto que un desafío de esta naturaleza requiere. Según un estudio del Banco Mundial, para el año 2050 la falta de acciones podría

\footnotetext{
Ceres BCA. Santiago, Chile

a Médico veterinario; ${ }^{\mathrm{b}}$ médico veterinario, $\mathrm{PhD}$

Recibido: 25/01/2018 Aprobado: 21/02/2018 En línea: 23/03/2018
}

Citar como: Gatica Eguiguren MA, Rojas H. Gestión sanitaria y resistencia a los antimicrobianos en animales de producción. Rev Peru Med Exp Salud Publica. 2018;35(1):118-25. doi: 10.17843/rpmesp.2018.351.3571. 
causar una pérdida de más del $5 \%$ del producto interno bruto en países de bajos ingresos, mientras que, a nivel mundial, impactaría negativamente sobre la pobreza, el comercio, la salud y la producción animal ${ }^{(4)}$.

Lo anterior evidencia la necesidad de implementar acciones para la reducción del uso de AM, junto con prevenir la generación y diseminación de la RAM, una de estas, es la aplicación de buenas prácticas sanitarias y del buen uso de antimicrobianos. Si bien hoy en día las exigencias de comercio internacional han obligado a la implementación, cada vez mayor, de este tipo de manejos en la producción y cadena alimentaria, en mercados nacionales, aún existen establecimientos productores con una precaria situación.

\section{RESISTENCIA A LOS ANTIBIÓTICOS}

La habilidad de adaptación natural de las bacterias le han conferido una enorme capacidad para desarrollar mecanismos que les permitan sobrevivir a la acción de agentes como los $\mathrm{AM}^{(1)}$.

En una población bacteriana, comensal o patógena, la aplicación de AM actuará inhibiendo o eliminando a todas aquellas bacterias cuya concentración mínima inhibitoria se encuentre debajo de la concentración del AM correspondiente ${ }^{(5-6)}$. A pesar de que los AM podrían guiar la selección de bacterias resistentes, su uso excesivo podría potenciar la presentación y diseminación de la RAM ${ }^{(1)}$.

Asimismo, la presión selectiva ejercida por los AM favorece la presentación de mutaciones y transferencia horizontal de elementos genéticos móviles que colaboran con la sobrevida y permanencia de genotipos bacterianos resistentes ${ }^{(7)}$.
A pesar de que la forma vertical es la más común para adquirir genes o factores de resistencia, es mediante la transferencia horizontal, donde ambientes de alta concentración bacteriana, como el sistema digestivo de animales y humanos, son ideales para este tipo de procesos ${ }^{(8)}$.

\section{PRODUCCIÓN ANIMAL Y EL USO DE ANTIMICROBIANOS}

Durante la producción animal, el uso de AM se encuentra asociado a un riesgo de generación de bacterias resistentes, las cuales posteriormente pueden ser diseminadas hacia la población humana, otros animales o el medio ambiente.

\section{RIESGOS DE GENERACIÓN}

Durante el ciclo de producción del animal en granja, estos se ven expuestos a una serie de bacterias comensales y patógenas. De acuerdo a la triada epidemiológica, las características del agente, el hospedero y el medio ambiente condicionan el desarrollo de enfermedades infecciosas ${ }^{(9)}$, que al tratarse de agentes bacterianos, los AM son, por excelencia, la herramienta para su control (Figura 1).

Muchos factores impactan de manera significativa en la generación de la RAM, entre estos tenemos: el uso innecesario, la aplicación prolongada, los tratamientos incompletos ${ }^{(5)}$, el uso de AM de mala calidad, la falta de indicaciones de quien prescribe el tratamiento, la aplicación de dosis incorrectas, la frecuencia de aplicación inadecuada, entre otros ${ }^{(10)}$. Esto, además de las condiciones de la misma bacteria, como la presencia de genes resistentes y las ventajas que le confieren su expresión, pueden gatillar la expresión de genes de resistencia ${ }^{(11)}$.

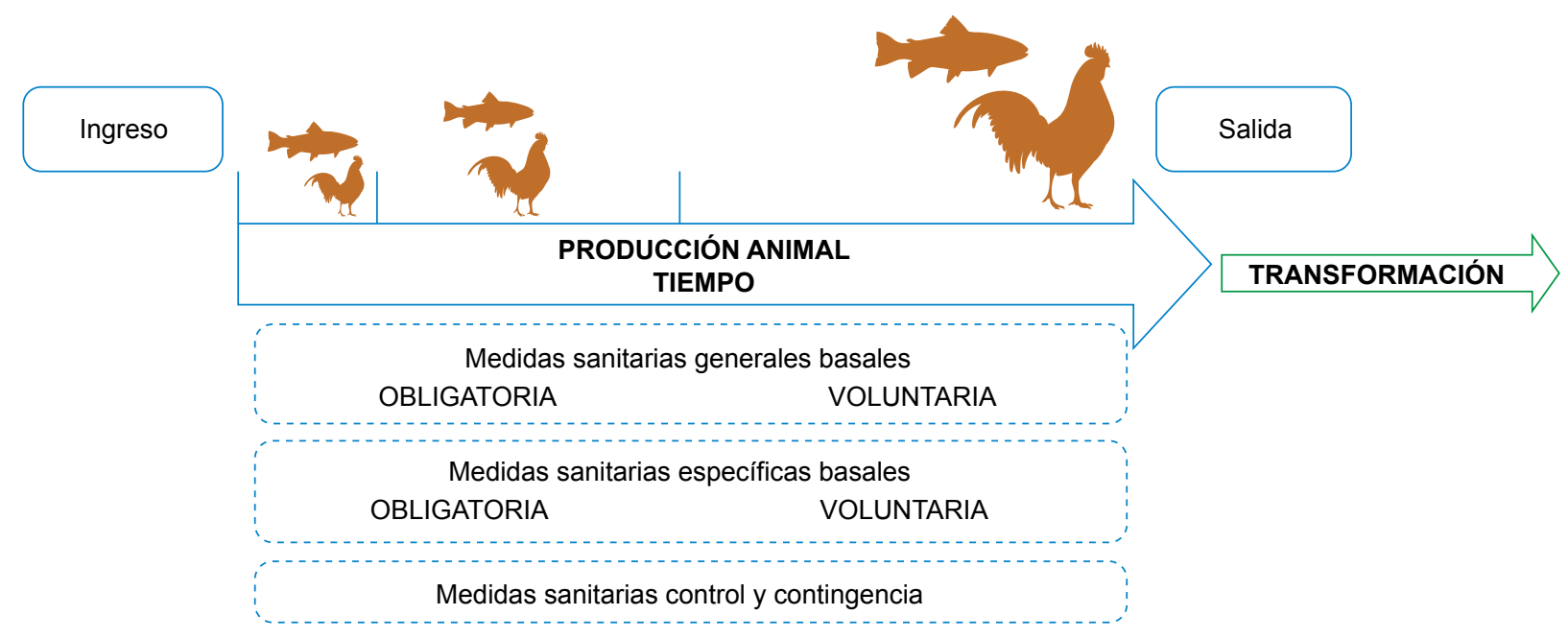

Fuente: elaboración propia

Figura 1. Representación de un sistema productivo animal. 
Los AM no son sólo utilizados con fines terapéuticos en producción animal, también pueden ser aplicados con fines profilácticos, metafilácticos y como promotores del crecimiento, este tipo de uso, a bajas dosis, ha demostrado ser un selector para la aparición de RAM desde las etapas iniciales de su aplicación. Un estudio prospectivo realizado el año 1975, evaluó los cambios en la flora intestinal de los animales y granjeros al introducir oxitetraciclina a bajas dosis como promotor de crecimiento. Los resultados demostraron la aparición de cepas de $E$. coli resistentes a tetraciclina y a otras drogas usadas en tratamientos para humanos ${ }^{(12)}$.

La vía de administración también juega un rol fundamental en la RAM. Una proporción importante de tratamientos con este tipo de fármacos son administrados a través de los alimentos, donde la inocuidad biológica, la correcta adición del antimicrobiano al alimento, la mezcla homogénea de sus ingredientes y la correcta mantención, son factores determinantes para la aplicación de una terapia apropiada y efectiva en los animales ${ }^{(13)}$.

\section{RIESGOS DE DISEMINACIÓN}

Las principales rutas de exposición de los humanos a bacterias resistentes provenientes de la producción animal son: el consumo de alimentos de origen animal, el contacto directo con animales de granja, y la contaminación ambiental y acuática por desechos de la producción animal (2). Estos dos últimos factores son también considerados como influyentes en el riesgo de exposición de los animales y el medio ambiente.

La presencia de bacterias resistentes a los AM en diversos alimentos de origen animal, ha sido ampliamente demostrada. Por ejemplo, estudios realizados en la Unión Europea donde se han aislado cepas de Campylobacter spp. en carne de aves, ha evidenciado un aumento de los porcentajes de resistencia a gentamicina desde un $0 \%$ a un 6,3 \%. En Estados Unidos, resistencia de cepas de E. coli a gentamicina, provenientes de carne de aves ha aumentado de $0 \%$ a 12,2 \%, desde el año 2007 al 2011 respectivamente ${ }^{(2)}$

El personal de la granja, médicos veterinarios, trabajadores de mataderos y otras personas que mantienen un contacto con animales de producción, se encuentran en riesgo de adquirir estas bacterias. Un estudio realizado en una granja de producción de pollos broiler tratados con AM, estimó que el riesgo de contagiarse con $E$. coli resistente a la gentamicina, en trabajadores en contacto directo con aves era 32 veces mayor que otras personas de la comunidad. Además, otras investigaciones han relacionado el contacto directo entre animales y trabajadores, encontrando los mismos genes de resistencia en ambos grupos ${ }^{(12)}$.
Por otro lado, los desechos animales, ya sean excrementos, aguas contaminadas y otros restos biológicos, contienen altas cargas de poblaciones bacterianas y, probablemente, genes de resistencia, los cuales se diseminan al ambiente principalmente a través de vectores y fómites. Cabe destacar que los excrementos, además de bacterias, contienen AM no metabolizados y metabolitos activos ${ }^{(14)}$, que generan una presión selectiva sobre la población bacteriana del ambiente donde son depositados. Un ejemplo de las vías de exposición desde la producción animal hacia la población humana se muestra en la Figura 2.

\section{GESTIÓN EN SANIDAD ANIMAL Y RESISTENCIAALOSANTIMICROBIANOS EN PRODUCCIÓN ANIMAL}

La gestión de la sanidad animal corresponde a un sistema diseñado para optimizar la sanidad física y del bienestar de los animales. Esta integra la prevención, el tratamiento $y$ el control de las enfermedades, y los trastornos que afectan a cada animal y al rebaño, incluyendo el registro de las enfermedades, lesiones, mortalidad y tratamientos médicos cuando fuera apropiada su aplicación ${ }^{(15)}$.

Actualmente existe una serie de manejos que permiten la prevención de la enfermedad y con ello la disminución del uso de AM. Entre las principales acciones preventivas se identifican las buenas prácticas de producción animal y la aplicación de medidas de bioseguridad. Adicionalmente, dado que el uso de AM en ciertas ocasiones es necesario, respetar las buenas prácticas en el uso de productos veterinarios es también fundamental. A pesar de esto, la aplicación de este tipo de estrategias en la producción animal es aún deficiente en una gran cantidad de productores.

\section{BUENAS PRÁCTICAS DE PRODUCCIÓN ANIMAL Y BIOSEGURIDAD}

La Organización de las Naciones Unidas por la Alimentación y Agricultura (FAO) y la Organización Mundial de Sanidad Animal (OIE), a través de su guía de buenas prácticas ganaderas para la seguridad sanitaria de los alimentos de origen animal (2009), entregan una serie de recomendaciones que contribuyen a la protección biológica, química y física en los sistemas de producción animal. Estas prácticas incluyen, entre otras, establecer medidas de gestión sanitaria que disminuyan la presentación de patógenos, impidan su multiplicación y eliminen posibles vías de transmisión de enfermedades. Para esto, se promueve la separación de animales enfermos y recién llegados del resto de la población; realizar un retiro eficaz de desechos (incluidos animales muertos), asegurar la limpieza y desinfección de materiales; realizar cambios de cama con regularidad; implementar un sistema de control 


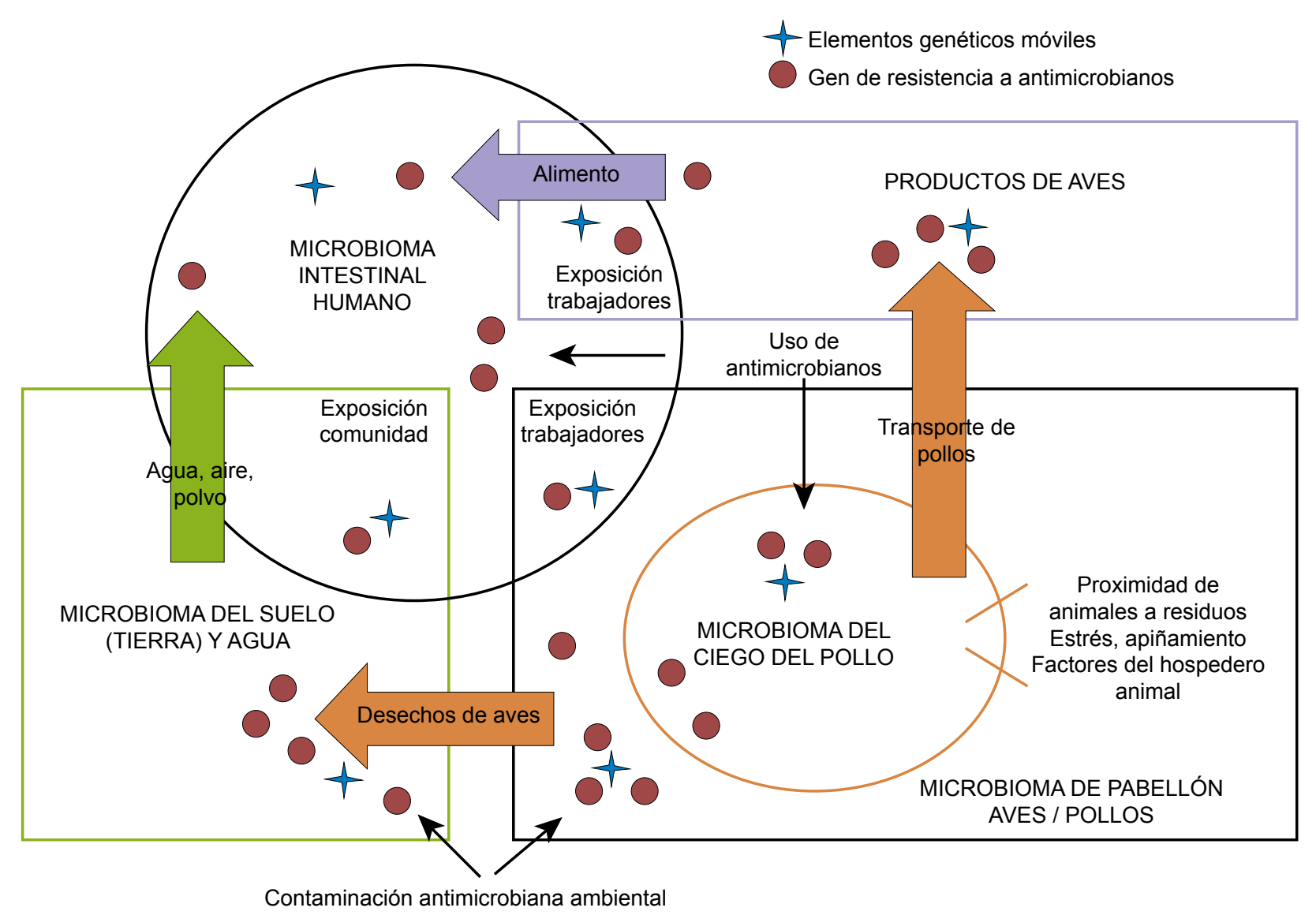

Fuente: You y Silbergeld ${ }^{(14)}$

Figura 2. Vías de exposición de la población humana a factores de resistencia a los antimicrobianos desde la producción animal.

de plagas; capacitar al personal y mantener registros de manejo y animales ${ }^{(16)}$.

\section{BUENAS PRÁCTICAS EN EL USO DE PRODUCTOS VETERINARIOS}

Si bien, en la guía de buenas prácticas la OIE y FAO se menciona el uso de productos veterinarios (16), estas organizaciones cuentan con capítulos especiales donde se detallan las directrices para el buen uso de los $\operatorname{AM}^{(17,18)}$. En estos se recalca que la aparición de RAM, no sólo ocurre por la aplicación, sino por el proceso de elaboración, comercialización y decisión de uso de AM. Frente a esto, la OIE establece una serie de responsabilidades para cada uno de los actores involucrados (Tabla 1. Responsabilidades de los actores de la cadena de fármacos veterinarios para el uso responsable y prudente de antimicrobianos en animales de producción.).

\section{PRODUCTOS ALTERNATIVOS AL USO DE ANTIMICROBIANOS EN LA PRODUCCIÓN ANIMAL}

En los últimos años se ha observado un fuerte interés y esfuerzo por investigar y desarrollar productos que permitan lograr disminuir el uso de AM en la producción animal, esto como complemento a las medidas de manejo.

Entre estas estrategias destaca la inmunización preventiva de los animales (2) a través de vacunas, que permitan disminuir las presentaciones clínicas de la enfermedad ${ }^{(19)}$. Por otro lado, la sanidad de la flora bacteriana intestinal ha demostrado ser un elemento de alta importancia en la prevención de enfermedades, debido a que contribuye con la funcionalidad del sistema inmune y la asimilación de nutrientes, disminuyendo la posibilidad de colonización por patógenos ${ }^{(2)}$.De esta forma, la adición de prebióticos en la alimentación animal, por ejemplo fibras dietarias, ologosacáridos y ácidos orgánicos, ayuda a modular la flora intestinal para beneficiar la salud del animal ${ }^{(19)}$.

Otra alternativa relativamente nueva es la utilización de fagos. Esta tecnología consiste en el uso de bacteriófagos para la neutralización específica y selectiva de patógenos. Los fagos son considerados más específicos que los antimicrobianos ${ }^{(2)}$, ya que solo actúan sobre las bacterias para los cuales han sido diseñados, previniendo además la disbiosis (alteración de la flora intestinal) ${ }^{(19)}$. 
Tabla 1. Responsabilidades de los actores de la cadena de fármacos veterinarios para el uso responsable y prudente de antimicrobianos en animales de producción.

\begin{tabular}{lcll}
\hline Etapa & Responsable & & \multicolumn{1}{c}{ Responsabilidades } \\
\hline \multirow{3}{*}{ Elaboración } & Autoridad & - & Realizar controles de calidad que aseguren las buenas prácticas de fabricación. \\
& sanitaria & - & Evaluación de la eficacia terapéutica. \\
& & - & Evaluación de los agentes para generar resistencia. \\
\hline
\end{tabular}

- Establecer e implementar procedimientos de registro legales y eficaces que evalúen la calidad, inocuidad y eficacia de los productos médicos veterinarios que contengan antibióticos.

- Entregar la licencia de comercialización, que debe realizarse de acuerdo a lo señalado en el Código Terrestre y Acuático de la OIE.

- En el caso de productos importados, solicitar que la industria farmacéutica presente certificados de calidad preparados por la autoridad competente del país exportador y fabricante, según corresponda.

- Realizar un análisis de riesgos y beneficios potenciales que pueden conllevar el uso de los Autoridad antimicrobianos para los animales y humanos.

competente - Realizar controles de calidad que aseguren las buenas prácticas de fabricación.

- Evaluar la eficacia terapéutica.

- Evaluar los agentes para generar resistencia.

- Determinar la ingesta diaria aceptable, del límite máximo de residuos y de los períodos de suspensión en los animales destinados a la producción de alimentos.

Comercialización

- Evaluar el impacto medio ambiental.

- Asegurar que los productos contengan la información necesaria sobre sus características.

- En cuanto al suministro, los antimicrobianos deben ser prescritos por un médico veterinario u otra persona autorizada para ello, son entregados sólo productos autorizados.

- Control de la publicidad de tal forma que sea compatible con el buen uso de antibióticos.

\begin{tabular}{ccl}
\hline Industria & - & Vender productos autorizados. \\
farmacéutica & - & Preparar certificaciones de calidad de la autoridad competente correspondiente. \\
veterinaria & - & Entregar a la autoridad la cantidad de antimicrobianos comercializados. \\
& - & Respetar las condiciones para la publicidad establecidas por la autoridad. \\
\hline Distribuidores & - & Distribuir antimicrobianos sólo cuando se disponga de una receta médico veterinario u otra \\
& - & $\begin{array}{l}\text { Mersona con la formación adecuada. } \\
\text { antibióticos. }\end{array}$ \\
& - & Mantener registros sobre los productos comercializados.
\end{tabular}

\begin{tabular}{|c|c|c|}
\hline $\begin{array}{l}\text { Decisión de } \\
\text { antimicrobiano }\end{array}$ & $\begin{array}{c}\text { Médicos } \\
\text { veterinarios/ } \\
\text { profesionales } \\
\text { responsables } \\
\text { de sanidad de } \\
\text { animales }\end{array}$ & $\begin{array}{l}\text { - } \quad \text { Tener formación en el uso responsable y prudente de antibióticos. } \\
\text { - } \quad \text { Realizar un examen clínico de los animales afectados previa administración del antibiótico. } \\
\text { - } \quad \text { Para la elección del antimicrobiano se debe considerar la lista OIE de los agentes } \\
\text { antimicrobianos de importancia veterinaria. } \\
\text { - } \quad \text { Experiencia clínica, perspicacia diagnóstica y juicio terapéutico. } \\
\text { - } \quad \text { Información de laboratorio diagnóstico y análisis de sensibilidad realizado en laboratorio } \\
\text { cuando sea posible. } \\
\text { - } \quad \text { Farmacodinamia. } \\
\text { - } \quad \text { Conveniencia del régimen de dosificación y vía de administración. } \\
\text { - } \quad \text { Farmacocinética y distribución del fármaco en los tejidos del animal a tratar. } \\
\text { - } \quad \text { Historial epidemiológico del establecimiento de producción, particularmente relacionado a los } \\
\text { perfiles de resistencia a los antibióticos. } \\
\text { - Uso de extra-etiqueta solo cuando no se disponga de antimicrobianos registrados } \\
\text { adecuados. }\end{array}$ \\
\hline
\end{tabular}




\section{Médicos}

veterinarios/ profesionales responsables de sanidad de animales
- Entregar un protocolo donde se detalle el tratamiento, precauciones y períodos de suspensión del antimicrobiano a utilizar.

En cuanto al registro de datos de los antimicrobianos utilizados:

- Cantidad de antimicrobiano utilizado por especie animal,

- Lista de antimicrobianos administrados a cada establecimiento de producción animal,

- Calendario de tratamiento que incluya el período de suspensión del antimicrobiano aplicado.

- Datos sobre susceptibilidad a los antibióticos.

- Comentarios sobre la respuesta de los animales al tratamiento antimicrobiano aplicado.

- Investigación de reacciones adversas a los tratamientos antibióticos, incluidas aquellas ausencias de respuesta debido a posible resistencia a estos agentes.

- Identificar posible resistencia a los antimicrobianos a las autoridades competentes.

- Revisar registro de uso de medicamentos veterinarios de tal forma de asegurar el cumplimiento de las instrucciones o prescripciones indicadas por él.

Relacionado a la evaluación de la respuesta:

- En caso de falla de un primer tratamiento, en lo posible utilizar pruebas confirmatorias de laboratorio, de lo contrario se debe aplicar un antimicrobiano apropiado de una clase o subclase distinta al ya aplicado.

- $\quad$ Elaborar junto al médico veterinario un plan sanitario que detalle medidas preventivas.

- Uso de antimicrobianos solo cuando estos han sido prescritos por un médico veterinario/ profesional responsable de sanidad de animales acuáticos.

- Contar con formación en el uso responsable y prudente de antibióticos.

- Utilizar antimicrobianos respetando las indicaciones de la etiqueta y la prescripción del médico veterinario/profesional responsable de sanidad de animales acuáticos.

- Aislar a los animales enfermos para evitar la transferencia de patógenos, eliminar animales muertos o moribundos rápidamente.

- Respetar las medidas de bioseguridad dentro de la explotación y aplicar precauciones básicas de higiene según corresponda.

- Utilizar productos antimicrobianos no caducos.

- Respetar y registrar los períodos de suspensión para evitar residuos en los alimentos de origen animal.

Criadores de

- Conservar informes de laboratorio relativos a pruebas bacteriológicas y de susceptibilidad. dando acceso al médico veterinario a estos datos.

En cuanto al registro de datos de los antimicrobianos utilizados se debe incorporar:

- Nombre del producto y sustancia activa, número de lote y fecha de caducidad.

- Nombre de quien receta y proveedor.

- Fecha de administración.

- Identificación del animal o grupo de animales a los que se administra el tratamiento con antibióticos.

- Enfermedades clínicas tratadas.

- Dosificación.

- Períodos de suspensión.

- Resultados de pruebas diagnósticas.

- Eficacia de la terapia.

Autoridad - Establecer vigilancia de RAM por el uso de antibióticos.

sanitaria - Asegurar que son administrados a los animales por un médico veterinario, supervisado por uno o aplicados por otra persona autorizada.

OIE:Organización mundial de Sanidad Animal

Fuente: Organización Mundial de Sanidad Animal. Uso responsable y prudente de agentes antimicrobianos en medicina veterinaria (17) Organización Mundial de Sanidad Animal. Uso responsable y prudente de agentes antimicrobianos en los animales acuáticos (18) 


\section{EXPERIENCIAS EN EL CONTROL DEL USO DE ANTIMICROBIANOS Y RESISTENCIAA LOS ANTIMICROBIANOS EN PRODUCCIÓN ANIMAL}

A pesar de ser complejo, existen ejemplos existosos de países que han establecido programas para la reducción del uso de AM en la producción animal para la contención de la RAM.

\section{MODELO DE LOS PAÍSES BAJOS}

Entre los años 1990 y 2007, el consumo de antimicrobianos en animales de los Países Bajos se duplicó. Esta situación los llevó a ser considerados el 2007 como el mayor consumidor de AM entre diez países de la Unión Europea. Junto con el alto uso de antibióticos, se detectaron importantes aumentos en la RAM a nivel de las granjas ${ }^{(20)}$.

Este problema incentivó la participación conjunta de todos los involucrados en la cadena de producción animal: productores, proveedores de alimentos para animales, asociaciones veterinarias y cuerpos gubernamentales, implementándose acciones, tanto regulatorias como voluntarias, que permitieron reducir en un $56 \%$ el uso de antimicrobianos en la producción animal entre los años 2007 y $2012^{(20)}$.

\section{MODELO PARA LA SALMONICULTURA CHILENA}

Actualmente, la enfermedad de mayor importancia para la salmonicultura chilena es la piscirickettsiosis. A pesar de los múltiples esfuerzos, el control más eficiente ha sido aplicación de AM. Situación que ha hecho que dicha enfermedad sea responsable de un $92,5 \%$ deluso de los antibióticos en la etapa de mar en el país ${ }^{(21)}$.

El alto consumo de AM ha sido una gran preocupación para la autoridad sanitaria de Chile. Por ello, desde el año 2010, el país ha optado por el fortalecimiento de sus programas de vigilancia y control de la enfermedad, ha realizado mejoras a las normativas relacionadas al uso de productos antimicrobianos en la salmonicultura y ha elaborado y aplicado un Programa sanitario general para uso de antimicrobianos en la Salmonicultura y otros peces de cultivo (2015).

Entre los requisitos normativos destaca la declaración obligatoria del uso de AM durante la producción, para esto, el servicio cuenta con un sistema de declaración online, además de estar implementado el sistema de receta veterinaria electrónica, que le permite la posibilidad de fiscalización inmediata. Adicionalmente, la autoridad desarrolló el Manual de Buenas Prácticas en el Uso de Antimicrobianos y Antiparasitarios en Salmonicultura Chilena ${ }^{(22) .}$

Conjuntamente, el servicio ha establecido como estrategia la reducción del uso de antimicrobianos en la producción salmonera, la certificación libre de tratamientos antimicrobianos y/o antiparasitarios para centros de engorda ${ }^{23)}$. Complementariamente, el sector público y privado se encuentran desarrollando iniciativas de productos alternativos al uso de antibióticos, tales como vacunas más eficaces ${ }^{(24)}$, generación de ovas más resistentes a piscirickettsiosis ${ }^{(25)}$, el estudio de péptidos terapéuticos, el uso de Aloe Vera como bactericida, entre otros ${ }^{(26)}$. Dichos esfuerzos han permitido, desde el año 2014, observar una disminución del uso de antimicrobianos en la salmonicultura chilena ${ }^{(21)}$.

\section{DESAFÍOS FUTUROS}

Existe aún una alta necesidad de desarrollar estrategias y productos que permitan reemplazar o disminuir el uso de antimicrobianos en la producción animal. Sin embargo, se debe continuar el refuerzo de medidas para la gestión sanitaria que permitan disminuir la necesidad de su aplicación. La imposibilidad de una completa eliminación de los antimicrobianos de la producción animal, hacen necesario continuar la concientización sobre su uso responsable y prudente.

Junto a lo anterior, la implementación de programas de vigilancia sobre el uso de antimicrobianos en la producción animal y la RAM son esenciales para reconocer la existencia, gravedad y ubicación del problema, lo que a su vez permite orientar las medidas a tomar.

Finalmente, la participación intersectorial bajo el enfoque Una Salud es y continuará siendo fundamental para la contención de la RAM. Sin embargo, para un mayor impacto, se necesita de la integración de todos los actores involucrados: instituciones gubernamentales, asociaciones, productores animales, proveedores de alimentos animales, industria farmacéutica, investigadores y consumidores.

Contribuciones de autoría: MAGE y HR han participado en la concepción del artículo, recolección de información, redacción y aprobación de la versión final.

Fuentes de financiamiento: la realización de este artículo no ha recibido financiamiento de ningún tipo.

Conflictos de interés: los autores del artículo no presentan conflictos de interés. 


\section{REFERENCIAS BIBLIOGRÁFICAS}

1. Moulin G. What is antimicrobial resistance? [Internet]. In: Antimicrobial resistance: characterisation and surveillance S1; 2013. [citado el 20 de enero de 2018]. Disponible en: http://www.oie.int/eng/A_AMR2013/Abstracts/S1_1_G\%C3\%A9rardMoulin.pdf

2. Economou V, Gousia P. Agriculture and food animals as a source of antimicrobialresistant bacteria. Infect Drug Resist. 2015;8:49-61. doi: 10.2147/IDR.S55778.

3. Robinson TP, Wertheim HF, Kakkar M, Kariuki S, Bu D, Price LB. Animal production and antimicrobial resistance in the clinic. Lancet. 2016;387(10014):e1-3. doi: 10.1016/S0140-6736(15)00730-8.

4. World Bank Group. Drug-Resistant Infections: A Threat to Our Economic Future [Internet]. Washington, DC: World Bank; 2017 [citado 20 de enero de 2018]. Disponible en: http:// documents.worldbank.org/curated/ en/323311493396993758/pdf/114679REVISED-v2-Drug-Resistant-InfectionsFinal-Report.pdf

5. Zaman SB, Hussain MA, Nye R, Mehta V, Mamun KT, Hossain N. A Review on Antibiotic Resistance: Alarm Bells are Ringing. Cureus. 2017;9(6):e1403. doi: 10.7759/cureus. 1403.

6. Silva J. Resistencia a los antibióticos. Rev Latinoam Microbiol. 2006;48(2):105-12.

7. Schwarz S, Loeffer A, Kadlec K. Bacterial resistance to antimicrobial agents and its impact on veterinary and human medicine. Vet Dermatol. 2017;28(1):82e19. doi: $10.1111 /$ vde. 12362 .

8. Acar JF, Moulin G. Antimicrobial resistance: a complex issue. Rev Sci Tech. 2012;31(1):23-31.

9. Jaramillo Arango CJ, Martínez Maya JJ. Epidemiología veterinaria. México: El Manual Moderno; 2010.

10. Errecalde JO. Uso de antimicrobianos en animales de consumo: incidencia del desarrollo de resistencias en salud pública [Internet]. Roma: Organización de las Naciones Unidas para la Agricultura y la Alimentación; 2004. [citado 20 de enero de 2018]. Disponible en: http://www.fao. org/tempref/docrep/fao/007/y5468s/ y5468s00.pdf

11. Food and Agriculture Organization of the United Nations. Drivers, Dynamics and Epidemiology of Antimicrobial Resistance in Animal Production [Internet]. Roma: FAO; 2016. [citado 15 de enero de 2018]. Disponible en: http:// www.fao.org/3/a-i6209e.pdf
12. Marshall B, Levy S. Food Animals and Antimicrobials: Impacts on Human Health. Clin Microbiol Rev. 2011;24(4):718-33. doi: 10.1128/ CMR.00002-11.

13. Filippitzi ME, Sarrazin $S$, Imberechts $H$, Smet A, Dewulf J. The risk of cross-contamination due to the use of antimicrobial medicated feed throughout the trail of feed from the feed mill to the farm. Food Addit Contam Part A Chem Anal Control Expo Risk Assess. 2016;33(4):644-55. doi: 10.1080/19440049.2016.1160442.

14. You Y, Silbergeld EK. Learning from agriculture: understanding low- dose antimicrobials as drivers of resistome expansion. Front Microbiol. 2014;5:284. doi: 10.3389/fmicb.2014.00284.

15. Organización Mundial de Sanidad Animal. Glosario. [Internet]. En: Código Sanitario para los Animales Terrestres. Paris: OIE; 2017. [citado 15 de enero de 2018]. Disponible en: http://www. oie.int/fileadmin/Home/esp/Health_ standards/tahc/current/glossaire.pdf

16. Organización de las Naciones Unidas por la Alimentación y Agricultura, Organización Mundial de Sanidad Animal. Guía de buenas prácticas ganaderas para la seguridad sanitaria de los alimentos de origen animal [Internet]. Roma: FAO and OIE; 2009. [citado el 15 de enero de 2018]. Disponible en: http://www.oie.int/fileadmin/Home/ esp/Current_Scientific_Issues/docs/pdf/ esp_guide.pdf

17. Organización Mundial de Sanidad Animal. Uso responsable y prudente de agentes antimicrobianos en medicina veterinaria [Internet]. En: Código Sanitario para los Animales Terrestres. Paris: OIE; 2016. [citado el 15 de enero de 2018]. En: http://www.oie.int/index. php $? \mathrm{id}=171 \& \mathrm{~L}=2 \&$ htmfile $=$ chapitre antibio_resp_prudent_use.htm

18. Organización Mundial de Sanidad Animal. Uso responsable y prudente de agentes antimicrobianos en los animales acuáticos [Internet]. En: Código Sanitario para los Animales Acuáticos. Paris: OIE; 2016. [citado 15 de enero de 2018]. En: http://www.oie.int/index. php?id $=171 \& \mathrm{~L}=2 \&$ htmfile $=$ chapitre antibio_resp_prudent_use.htm

19. Allen HK, Levine UY, Looft T, Bandrick M, Casey T. Treatment, promotion, commotion: antibiotic alternatives in food-producing animals. Trends Microbiol. 2013;21(3):114-9. doi: 10.1016/j.tim.2012.11.001.
20. Speksnijde DC, Mevius DJ, Bruschke CJM, Wagenaar JA. Reduction of Veterinary Antimicrobial Use in the Netherlands. The Dutch Success Model. Zoonoses Public Health. 2015;62 Suppl 1:79-87. doi: 10.1111/zph.12167.

21. Servicio Nacional de Pesca y Acuicultura. Informe sobre uso de antimicrobianos por la Salmonicultura nacional [Internet]. Valparaíso: Subdirección de Acuicultura, Departamento de Salud Animal; 2016. [citado 15 de enero de 2018]. Disponible en: http://www.sernapesca.cl/presentaciones/ Comunicaciones/Informe_Sobre_Uso_ de_Antimicrobianos-201612_20171205. pdf

22. Servicio Nacional de Pesca y Acuicultura [Internet]. Valparaíso: SERNAPESCA; 2018. [citado el 17 de enero de 2018]. Control de productos farmacéuticos [1 pagina]. Disponible en: http://www. sernapesca.cl/index.php?option $=$ com content $\&$ view $=$ article $\&$ id $=133 \&$ Ite$\operatorname{mid}=295$

23. Servicio Nacional de Pesca y Acuicultura. Procedimientos para la certificación de peces libres de tratamientos antimicrobianos y/o antiparasitarios para centros de engorda [Internet]. Valparaíso: Departamento Salud Animal, SERNAPESCA; 2017 [citado 9 de febrero de 2018]. Disponible en: http://www.sernapesca.cl/index.php?option $=$ com_remository\&Itemid $=246 \&$ func $=$ startdown\&id $=20475$

24. Anuncian vacunas más efectivas para la industria del salmón [Internet]. Aqua. Publicado el 2 de mayo del 2017. [citado el 9 de febrero de 2018]. Disponible en: http:// www.aqua.cl/2017/05/02/anuncian-vacunas-mas-efectivas-la-industria-del-salmon/

25. Lanzan ovas de salmón coho con alta resistencia al SRS [Internet]. Aqua. Publicado el 29 de junio del 2017. [citado el 9 de febrero de 2018]. Disponible en: http://www.aqua.cl/2017/06/29/lanzanovas-salmon-coho-alta-resistencia-al-srs/

26. Dos desarrollos buscan disminuir el uso de antimicrobianos en salmonicultura [Internet]. Aqua. Publicado el 2 de agosto del 2017. [citado el 9 de febrero de 2018]. Disponible en: http://www.aqua. cl/2017/08/02/dos-desarrollos-buscandisminuir-el-uso-de-antibioticos-ensalmonicultura/

Correspondencia: María de los Angeles Gatica Dirección: Avenida Apoquindo 3401, oficina 21, Las Condes. Santiago, Chile.

Correo electrónico: angeles.gatica@ceresbca.cl 